\title{
A model postulating a pivotal role of the levator- depressor neuro-muscular systems in locomotion of the stick insect
}

\author{
Tibor I Toth*, Silvia Daun-Gruhn \\ From 24th Annual Computational Neuroscience Meeting: CNS*2015 \\ Prague, Czech Republic. 18-23 July 2015
}

Locomotion of stick insects has been intensively studied for many years. These studies made use of both behavioural [1,2] and electrophysiological e.g. [3,4] methods. In addition, models have been constructed to mimic the locomotion (normal walking) of these insects e.g. [5]. All these studies have substantially advanced our knowledge on insect locomotion. Nevertheless, there still exist a large number of unresolved problems in this field. One of them is about the possibly hierarchical organization of the coordinated movements of the leg-joints during normal walking. The existing experimental data relating to this problem have not proved decisive. A modelling approach would therefore seem particularly apt to contribute to the resolution of this problem. The advantage of this method is that a wide range of scenarios and hypothetical experimental arrangements can be emulated by a model that bears the main hallmarks of its biological counterpart.

We followed exactly this route when investigating the organization of locomotion. We thus extended an earlier model of ours [6] that emulates the coordinated muscle activities in a single (middle) leg of the stick insect to include all three ipsilateral legs. The model of each leg consisted of the three main neuro-muscular systems that correspond to the three main antagonistic muscle pairs: $\mathrm{m}$. protractor and retractor coxae, $\mathrm{m}$. levator and depressor trochanteris and $\mathrm{m}$. extensor and flexor tibiae. The muscles were activated by corresponding motoneurones which, in turn, were controlled by the activity of non-spiking pre-motor interneurones and the activity of central pattern generators (CPGs). Our basic assumption was that the levator-depressor systems of each leg

\footnotetext{
* Correspondence: ttoth0@uni-koeln.de

Heisenberg Research Group of Computational Biology, Institute of Zoology, University of Cologne, 50674 Cologne, Germany
}

play a pivotal role in the organization of the coordinated movement of the three ipsilateral legs. According to our reasoning, the most reliable signal that affects normal stepping during locomotion is ground contact (touchdown) and lift-off. Both of them are, in essence, brought about by vertical movement of the femur of the leg, that is by proper activation of the levator-depressor neuromuscular system.

We tested this assumption accordingly in simulations with the model. In doing so, we succeeded in mimicking both the tetrapod and the tripod coordination patterns, which stick insects exhibit during normal walking. Moreover, we found that the coordination process in tripod only requires position signals of the legs whereas in tetrapod angular velocity signals, too, are necessary for the coordination. We also succeeded in modelling the transition between these coordination patterns and found that the switch is, in some sense, easier from tripod to tetrapod than in the opposite direction. The model thus supports our assumption on the pivotal role of the levator-depressor neuro-muscular system in normal walking.

\footnotetext{
Acknowledgements

This work has been funded by the Deutsche Forschungsgemeinschaft Grants DA1182/1-1 and GR3690/4-1.

Published: 18 December 2015

\section{References}

1. Cruse $\mathrm{H}$ : What mechanisms coordinate leg movement in walking arthropods? TINS 1990, 13:15-21.

2. Graham D: A behavioural analysis of the temporal organisation of walking movements in the 1 st instar and adult stick insect (Carausius morosus). J Comp Physiol A 1972, 81:23-52.

3. Borgmann $A$, Scharstein $H$, Büschges $A$ : Intersegmental coordination: influence of a single walking leg on the neighboring segments in the stick insect walking system. J Neurophysiol 2007, 98:1685-1696.
} 
4. Borgmann A, Hooper SL, Büschges A: Sensory feedback induced by frontleg stepping entrains the activity of central pattern generators in caudal segments of the stick insect walking system. J Neurosci 2009, 29:2972-2983.

5. Cruse H, Kindermann T, Schumm M, Dean J, Schmitz J: Walknet - a biologically inspired network to control six-legged walking. Neural Networks 1998, 11:1435-1447.

6. Knops S, Toth TI, Guschlbauer C, Gruhn M, Daun-Gruhn S: A neuromechanical model for the neuronal basis of curve walking in the stick insect. J Neurophysiol 2013, 109:679-691.

doi:10.1186/1471-2202-16-S1-P49

Cite this article as: Toth and Daun-Gruhn: A model postulating a pivotal role of the levator-depressor neuro-muscular systems in locomotion of the stick insect. BMC Neuroscience 2015 16(Suppl 1):P49.

Submit your next manuscript to BioMed Central and take full advantage of:

- Convenient online submission

- Thorough peer review

- No space constraints or color figure charges

- Immediate publication on acceptance

- Inclusion in PubMed, CAS, Scopus and Google Scholar

- Research which is freely available for redistribution

Submit your manuscript at www.biomedcentral.com/submit
( Biomed Central 